

San Juan Bautista en meditación

\section{EL BOSCO. EL TEMPO \\ Y EL TIEMPO DE \\ CONTEMPLACIÓN}

La exposición del V centenario.

Madrid, Museo Nacional

del Prado
Un grupo de alumnas me llama y dice: «Cori, a esta exposición hay que ir, imóntanos una visita guiada!». Nos ponemos en marcha para organizar la visita, y el protocolo de compra de entradas nos da la dimensión de la locura que es esta exposición y su éxito de público.

Ya en la exposición, un reloj digital marcó nuestro acceso a la sala a las 14:45 h. Y allí nos encontramos ante una multitud, entre veinte y treinta personas delante de cada obra, en un inteligente montaje que permitía ver algunas de las piezas por delante y por detrás. Iniciamos nuestro recorrido intentando gozar de la solvencia pictórica de este artista. Recrear, como acostumbramos a hacer en nuestras visitas, el tiempo de creación, lento y minucioso. Acercándonos, tanto como el museo permite, a cada tabla para observar esta pintura llena de detalles, algunos milimétricos. Buscando el porqué de cada icono y reconociendo la imposibilidad de esclarecer su personal y contextualizado diccionario. Disfrutando del cómo de las capas de pintura finas que sumadas nos hablan de transparencias y recrean ambientes.

Hablamos también de la peculiaridad de la obra de este curioso artista, como solo las mujeres sabemos hacer, ya que nuestra creatividad ha fructificado al margen del relato oficial, allí donde lo peculiar es compartido sin la norma como modelo.

Sin embargo, todo ello forzado, incluso frustrante. Todo intento de parar el reloj interno para entrar en el tiempo de la contemplación nos era negado 
por la presión del público a nuestras espaldas. Nos recordaban, con miradas y gestos acuciantes, que nuestro «tiempo» era excesivo.

El montaje expositivo y la presión del público, que como nosotras disponía de un tiempo limitado para ver la obra de El Bosco, nos empujaban a consumir, más que a ver las obras. Cuando precisamente estas obras se niegan a ser consumidas.

Retrocedamos en el tiempo e imaginemos a Mencía de Mendoza y Fonseca (1508-1554), una noble coleccionista de arte de la que sabemos que era ferviente admiradora de El Bosco. ¿Cuántas obras de este artista pudo ver en su vida? ¿Cuántas horas dedicó a cada tabla? ¿Qué tiempo se permitió y cuánto tiempo, su tiempo, le permitió? Imaginemos la vida de una noble a principios del siglo xvı delante de El carro de Heno, del que sabemos que encargó al taller de El Bosco una réplica.

Mencía, con un tempo de observación de las tablas del Bosco que nos hace pensar más en la calma de la oración que en las prisas de la acción. Me imagino a Mencía leyendo más que mirando una obra que, por sus detalles, no puede ser aprendida, que no se deja retener, porque nuestra retina no la puede copiar. De la misma manera que la música tardomedieval del contexto de El Bosco no es fácil de recordar porque ambos, pintura y música, son de otro tiempo.

La exposición de El Prado nos puso en un estado físico que podríamos llamar alterado. Al salir, ya en la cafetería del museo, intentando comprender y ponerle palabras, lo llegamos a calificar de estresado. ¿Podéis imaginar qué sabía el señor Jheronimus van Aken, nombre original de El Bosco, del estrés? Cincuenta y dos obras seguidas de El Bosco y otros pintores coetáneos, una detrás de otra y con la presión de no poder dedicarles más que unos minutos a cada una. jEl mismo pintor nunca vio en su taller tantas tablas suyas juntas!

Pero el acto de contemplación, lo que las obras de El Bosco reclaman desde hace quinientos años, lo reclaman nuestros cuerpos en un día a día que nos em- puja a consumir incluso aquello que de consumo nada sabe. Cada obra de arte puede ser una máquina para viajar en el tiempo, para conectar con miedos y gozos de siglos allá que nos hablan de miedos y gozos nuestros, para traspasar centurias encontrando lo que de en común tenemos todas y todos, más allá de nuestro contexto.

La obra de El Bosco ha hecho correr litros de tinta en un intento desesperante por explicar su peculiaridad y esclarecer su misterio, cuando su peculiaridad y su misterio se hallan en poner ojos de Mencía de Mendoza y Fonseca y darse la calma necesaria para recrear el tiempo de creación. Gozar y temer sus perversiones e invenciones con la calma de un cuerpo que no puede gozar y temer al mismo tiempo y con prisas.

Y por el placer de devolverle a El Bosco lo que la exposición del $V$ centenario le quitó, revivo aquello que desde mis catorce años de edad permanece intacto en el recuerdo de mi primer encuentro con esta obra y lo que con conocimientos, madurez, sensibilidad y amor por la pintura, se ha ido elaborando. Recuerdos que hablan de miedos a ser penetrada por orificios aún sin explorar. Miedo a las torturas más sofisticadas que nos hablan de la capacidad humana de inventar el horror en nombre del demonio o de Dios. Miedo a la perversión, que permite que el mismo miedo se vista de decálogo del buen comportamiento. Recuerdos que hablan de gozo por lo que la imaginación nos puede ofrecer cuando no ponemos filtros ni trabas y la desinhibición campa por nuestro cuerpo estremeciéndonos. Gozo por lo que las formas, construidas sin límites, son capaces de inventar en seres medio vegetales, medio animales o todo a la vez. Gozo y amor por la pintura paciente, la que se construye con pincel hábil, conocedor de recursos que moldean la materia para placer del ojo, con invenciones tanto técnicas como perceptuales que también atraviesan siglos, convirtiendo el tiempo de la contemplación en una necesidad a defender en nuestros cuerpos apresados por una sociedad que busca el «comprender urgente» sin el «con aprender». 